\title{
PEMANFAATAN FITOPLANKTON SEBAGAI BIOINDIKATOR KUALITAS AIR DI PERAIRAN MUARA SUNGAI HITAM KABUPATEN BENGKULU TENGAH PROVINSI BENGKULU
}

\author{
Harun Al Rasyid, Dewi Purnama, Aradea Bujana Kusuma \\ Program Studi IImu Kelautan Universitas Bengkulu \\ Email: harunalrasyid506@gmail.com
}

Received March 2018, Accepted April 2018

\begin{abstract}
ABSTRAK
Fitoplankton merupakan salah satu bioindikator untuk memantau tingkat pencemaran suatu perairan. Tingkat pencemaran ditentukan berdasarkan indeks saprobitas melalui analisis komposisi dan kelimpahan fitoplankton. Penelitian ini dilakukan pada bulan Agustus 2017 di Perairan Muara Sungai Hitam, Kabupaten Bengkulu Tengah, Provinsi Bengkulu dengan menggunakan metode survei. Jenis fitoplankton yang diperoleh dari hasil penelitian terdiri dari 4 kelas dan 22 spesies dengan komposisi spesies terbanyak terjadi pada kelas Bacillariophyceae dan yang terendah terjadi pada kelompok fitoplankton kelas Dinophyceae. Rata-rata kelimpahan fitoplankton pada muara Sungai Hitam sebanyak 322 ind/L tergolong dalam kelimpahan rendah, yang mecerminkan kesuburan perairan yang rendah. Berdasarkan nilai indeks saprobitas yang didapati perairan muara Sungai Hitam tergolong dalam tingkat saprobitas perairan $\beta-M e s o / O l i g o$ saprobik, yang diindikasikan telah terjadi pencemaran bahan organik ringan.
\end{abstract}

Kata Kunci : Bioindikator, Fitoplankton, Saprobik, Muara Sungai Hitam

\begin{abstract}
The water quality changing can be shown on physics, chemistry and the biologycal indicator of phytoplankton composition and the abundant are of water polution using saprobic index. This research was conducted on August 2017 and located in Sungai Hitam, Central Bengkulu, Bengkulu Province. Survey method used in this research. Totally, there are 4 class and 22 species found. Bacillariophyceae was higest and Dinophyceae was lowest found in location. The averge of abundant of phytoplankton in Sungai Hitam was 322 ind/L, the abundant of phytoplankton was chategoryzed into low chategoryzed that can be shown from low
\end{abstract}


fertilization. According the saprobic index value, Sungai Hitam was indicated contamination of organic material or $\beta-M e s o / O l i g o$ saprobic.

Keywords : Bioindicator, Phytoplankton, Saprobic, Sungai Hitam Estuary

\section{PENDAHULUAN}

Muara Sungai Hitam merupakan wilayah peralihan antara perairan darat dan perairan laut. Kondisi ini diduga dapat memberikan pengaruh terhadap penurunan kualitas lingkungan yang terlihat dengan kondisi fisik air yang berwarna coklat-kehitaman. Menurut Zahidin (2008) perubahan kualitas perairan dapat diketahui dari berubahnya kondisi fisik, kimia dan biologi. Sebagai indikator biologi komposisi dan kelimpahan fitoplankton dapat memberikan petunjuk untuk memantau terjadinya pencemaran dengan menggunakan indeks saprobitas, yang digunakan untuk melihat tingkat saprobitas perairan (Zahidin, 2008). Penelitian ini bertujuan untuk mengetahui kelimpahan fitoplankton dan peranan fitoplankton untuk meninjau keadaan kualitas air dengan menggunakan penghitungan saprobitas perairan pada perairan muara Sungai Hitam, Kabupaten Bengkulu Tengah, Provinsi Bengkulu.

\section{MATERI DAN METODE}

Penelitian ini dilaksanakan pada bulan Agustus 2017, dimana lokasi pengambilan data bertempat di perairan muara Sungai Hitam, Kabupaten Bengkulu Tengah, Provinsi Bengkulu.

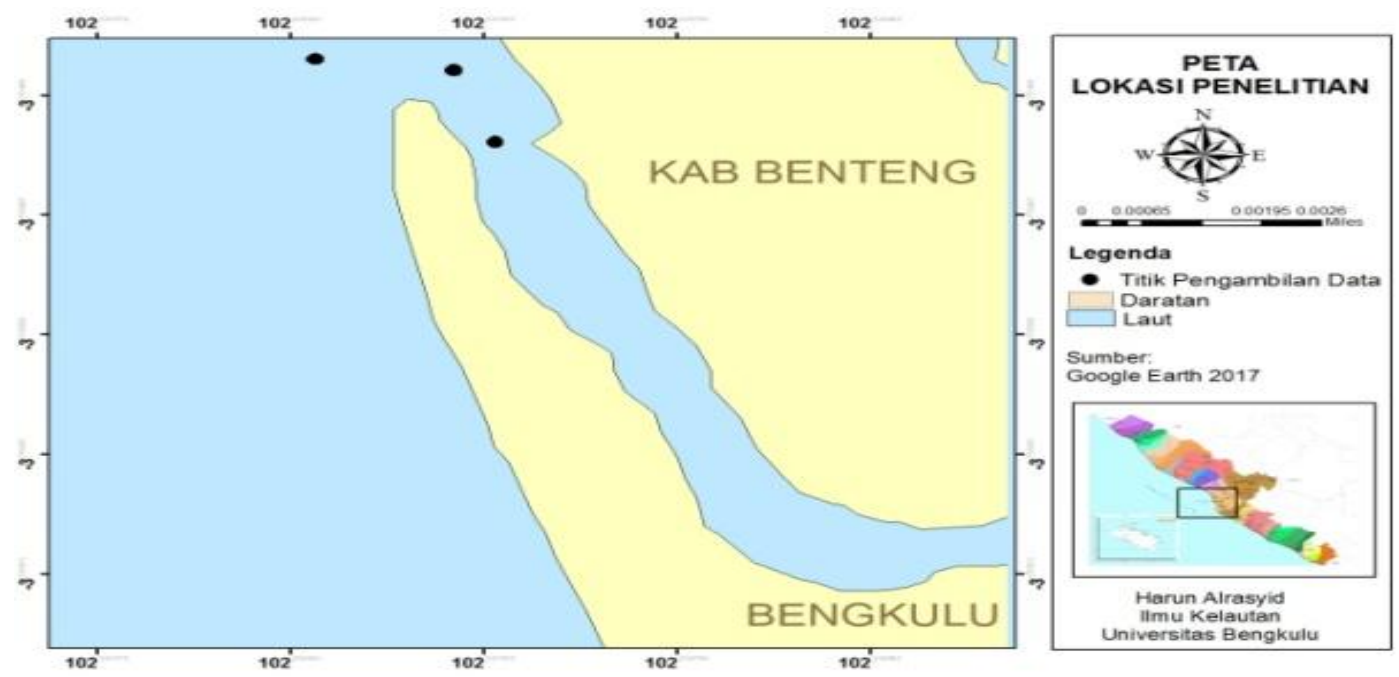

Gambar 1. Peta Lokasi Penelitian 


\section{Prosedur Penelitian}

\section{Pengumpulan Data}

Metode dalam pengumpulan data dengan menggunakan metode survei, yaitu penelitian dilakukan secara langsung terhadap objek tanpa memberikan perlakuan khusus terhadap objek yang diteliti (Rikardo, 2016).

\section{Penentuan Lokasi Penelitian}

Penentuan lokasi sampling pada penelitian ini menggunakan purposive sampling yaitu cara penentuan titik pengambilan sampel air dengan melihat pertimbangan-pertimbangan yang dilakukan oleh peneliti (Ali, dkk., 2013). Penggunaan metode ini agar peneliti dapat mengetahui kelimpahan fitoplankton dan saprobitas perairan berdasarkan karakteristik masing-masing stasiun di sekitar muara Sungai Hitam.

Lokasi pengambilan sampel air ditetapkan sebanyak tiga stasiun pengamatan yaitu Stasiun I, Stasiun II dan Stasiun III, dimana setiap stasiun terdiri dari sembilan titik sampling untuk pengambilan sampel air yang akan ditandai titik koordinatnya dengan menggunakan GPS.

\section{Prosedur Kerja}

\section{Pengambilan Sampel Fitoplankton}

Pengambilan sampel fitoplankton dilakukan di tiap-tiap titik yang telah ditentukan pada pukul 10.00-13.00 WIB untuk mewakili kondisi optimal cahaya matahari. Pengambilan sampel fitoplankton dilakukan dengan menyaring air sebanyak 50 L, yang disaring menggunakan planktonnet dengan ukuran mata jaring $35 \mu \mathrm{m}$. Sampel air yang tersaring dimasukkan ke dalam botol sampel $100 \mathrm{ml}$ diberi formalin $4 \%$ dan lugol $4 \%$, kemudian dimasukkan ke dalam ice box untuk dibawa ke Laboratorium Perikanan, Universitas Bengkulu.

\section{Pengambilan Data Parameter Lingkungan}

Pengukuran parameter lingkungan bertujuan untuk mengetahui kondisi perairan Muara Sungai Hitam yang dapat mempengaruhi kehidupan fitoplankton. Pengukuran parameter lingkungan meliputi suhu, salinitas, kecerahan, kecepatan arus dan derajat keasaman $(\mathrm{pH})$ perairan. Untuk pengukuran DO (Dissolved Oxygen) dan BOD (Biological Oxygen Demand) dengan menggunakan cara titrasi yang dilakukan di Laboratorium Perikanan, Universitas Bengkulu. Pengukuran kadar Nitrat $\left(\mathrm{NO}_{2}\right)$, Nitrit $\left(\mathrm{NO}_{3}\right)$ dan Fosfat $\left(\mathrm{PO}_{4}\right)$ dianalisis di Laboratorium Lingkungan Hidup, Provinsi Bengkulu. 


\section{Pengolahan Data}

\section{Identifikasi Jenis Fitoplankton}

Identifikasi sampel dilakukan dengan menggunakan bantuan mikroskop dengan perbesaran 10 kali sampai 100 kali.Identifikasi fitoplankton dilakukan dengan menggunakan buku identifikasi Yamaji (1979) dan Mizuno (1979).

\section{Analisis Kelimpahan}

Penentuan kelimpahan fitoplankton dihitung dengan rumus sebagai berikut (APHA, 1979 dalam Yati, 2015):

$$
\mathrm{N}=\frac{\mathrm{Vt}}{\mathrm{Vs}} \mathrm{x} \frac{1}{\mathrm{Vd}} \mathrm{xn}
$$

Keterangan:

$\mathrm{N}=$ Jumlah individu fitoplankton perliter

$\mathrm{Vt}=$ Volume air yang tersaring $(\mathrm{ml})$

$\mathrm{Vs}=$ Volume air pada sampel $\operatorname{preparad}(\mathrm{ml})$

$\mathrm{Vd}=$ Volume air yang disaring (Liter)

$\mathrm{n}=$ Jumlah fitoplankton yang tercacah

\section{Saprobik Indeks (SI)}

Untuk menghitung saprobitas perairan digunakan analisis trosap yang nilainya ditentukan dari Saprobik Indeks (SI) untuk menentukan tingkat pencemaran dengan persamaan (Maresi, dkk., 2015 dalam Rikardo, 2016):

$$
X=\frac{C+3 D-B-3 A}{A+B+C+D}
$$

Keterangan:

$X=$ Koefisien Saprobik

A =Jumlah Genus/Spesies organismePolisaprobik (Cyanophyta)

B =Jumlah Genus/Spesies organismea-Mesosaprobik (Dinophyta)

C = Jumlah Genus/Spesies Organismeß-Mesosaprobik (Chlorophyta)

D =Jumlah Genus/Spesies organismeOligosaprobik (Chrysophyta)

\section{HASIL DAN PEMBAHASAN}

\section{Klasifikasi Jenis Fitoplankton}

Komposisi fitoplankton yang dijumpai pada perairan muara Sungai Hitam berdasarkan hasil identifikasi terdiri dari 4 kelas dan 22 spesies. Kelas Chlorophyceae ditemukan dengan jumlah spesies yang tinggi dibandingkan kelas lainnya dengan 10 spesies, hal ini diduga karena 42 
kondisi perairan yang tenang dapat menunjang fitoplankton dalam kelas Chlorophyceae untuk berkembangbiak. Sesuai dengan pernyataan Arinardi, dkk., (1997) dalam Yati (2015) untuk kelas Chlorophyceae biasannya ditemukan melimpah pada perairan yang relatif tenang. Hal ini terlihat dari kondisi kecepatan arus pada lokasi penelitian yaitu sebesar $1,18 \mathrm{~cm} /$ detik, dimana kecepatan arus dengan nilai $<10 \mathrm{~cm} /$ detik tergolong dalam perairan dengan arus sangat lemah (Mason, 1981 dalam Yati, 2105). Pada kelas Cyanophyceae sebanyak 3 spesies, kelas Bacillariophyceae sebanyak 8 spesies dan pada kelas Dinophyceae sebanyak 1 spesies.

Pada kelas Dinophyceae ditemukan dengan jumlah spesies yang rendah, diasumsikan karena lokasi penelitian yang tergolong dalam daerah estuari ini rentan mengalami perubahan, sehingga dapat menyebabkan fitoplankton pada kelas Dinophyceae sulit untuk berkembang. Hal ini dikarenakan antara 1000-1500 spesies dari Dinophyceae menempati lingkungan laut dan air tawar, sebagian besarnya lebih dari $90 \%$ hidup di laut (Sunarto, 2008).

Komposisi fitoplankton dianalisis berdasarkan kelimpahan pada masing-masing kelas, sehingga diperoleh nilai (\%) kelas mana yang banyak dijumpai di perairan muara Sungai Hitam yang dapat dilihat secara lengkap pada Gambar 2 berikut.

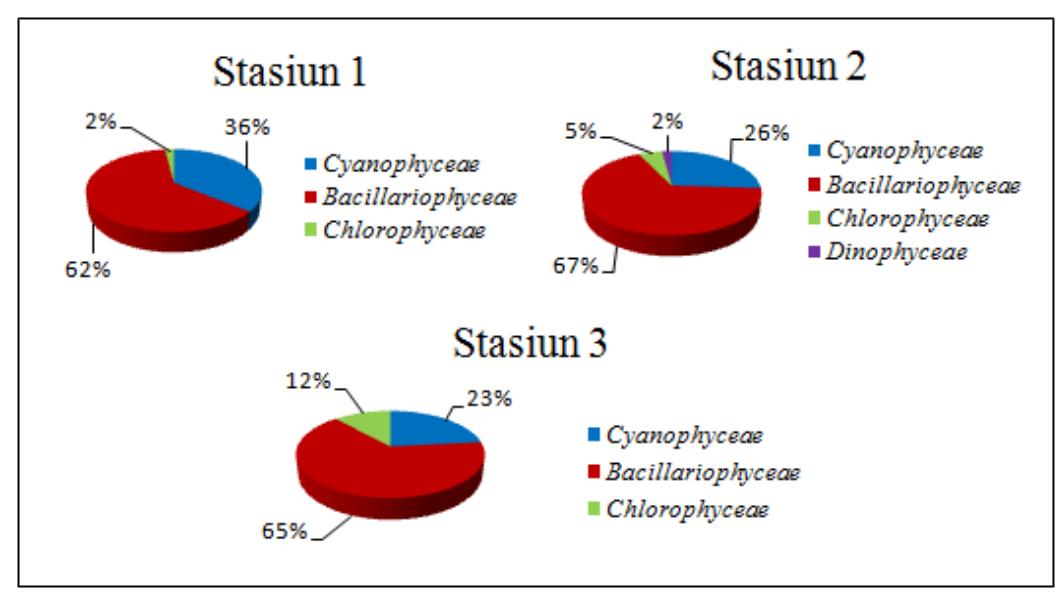

Gambar 2. Komposisi Kelas Fitoplankton

Kelompok fitoplanktonkelas Bacillariophyceae merupakan kelas dengan nilai komposisi yang tertinggi, dibandingkan dengan kelas fitoplankton lainnya (Gambar 2). Hal ini diduga fitoplankton pada kelas Bacillariophyceae memang umum ditemui pada perairan muara, karena memiliki tingkat toleransi dan adaptasi yang baik terhadap perubahan lingkungan. Senada dengan pernyataan Nybakken (1988) dalam Zahidin (2008) plankton di muara sungai didominasi oleh jenis diatom, karena fitopankton pada kelas Bacillariophyceae mampu beradaptasi dengan perubahan faktor lingkungan diantaranya nutrien, salinitas dan penetrasi cahaya (Widianingsih, dkk., 2007 dalam Suryanti, 2016). 
Pada kelas Chlorophyceae dan Cyanophyceae didapati nilai komposisi yang mengalami perubahan dari Stasiun 1 hingga Stasiun 3, baik perubahan nilai yang mengalami penurunan maupun perubahan nilai komposisi yang meningkat (Gambar 2).

Perubahan nilai komposisi fitoplankton pada kelas Chlorophyceae dan pada kelas Cyanophyceae diduga merupakan imbas dari perubahan kondisi perairan. Senada dengan pendapat Wulandari (2015) perubahan kondisi fisika-kimia perairan menyebabkan adanya perbedaan dari struktur komunitas plankton khususnya fitoplankton.

Pada kelas Dinophyceae hanya didapati satu spesies fitoplankton yaitu Ceratium sp. dan merupakan kelas dengan komposisi terendah pada lokasi penelitian, karena hanya dapat ditemui pada Stasiun 2 (Gambar 2). Hal ini dikarenakan fitoplankton pada kelas Dinophyceae merupakan fitoplankton yang kehidupannya menempati lingkungan laut ataupun air tawar (Sunarto, 2008). Sehingga lokasi penelitian yang tergolong dalam perairan muara diduga berimbas pada perkembangan fitoplankton pada kelas Dinophyceae ini. Senada dengan pendapat Suryanti (2016) umumnya pada daerah muara sungai kondisi salinitas mengalami perubahan dari waktu ke waktu, sehingga jenis-jenis fitoplankton yang hidup di wilayah ini adalah jenis yang memiliki toleransi terhadap perubahan salinitas.

\section{Kelimpahan Fitoplankton}

Pada kelas Bacillariophyceae spesies Isthmia sp. dan kelas Cyanophyceae spesies Phormodium sp. merupakan yang paling banyak muncul pada tiap Stasiun penelitian, yang tersaji pada Gambar berikut.

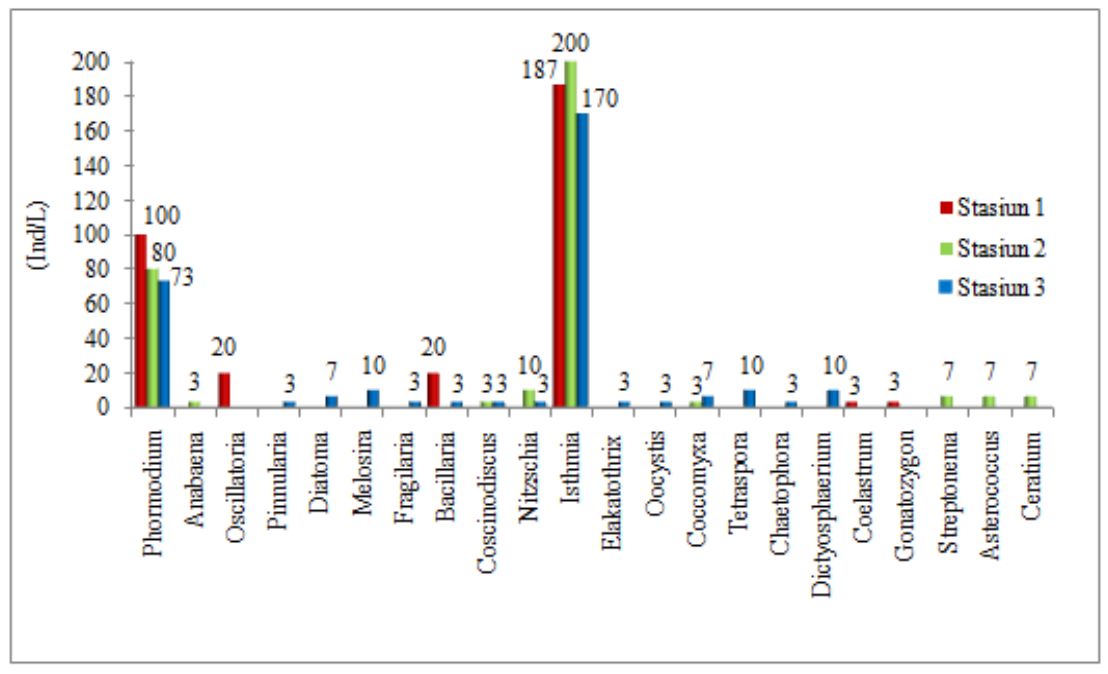

Gambar 3. Kelimpahan Spesies Fitoplankton

Didapati spesies Isthmia sp. memiliki nilai kelimpahan total tertinggi sebesar 557 Ind/L dan diikuti Phormodium sp. dengan nilai 253 Ind/L. Nilai 
kelimpahan yang tinggi pada spesies Isthmia sp. yang termasuk dalam kelas Bacillariophyceae ini diduga karena menurut Rikardo (2016) fitoplankton pada kelas Bacillariophyceae mampu mempertahankan hidupnya dan mengembangbiakkan dirinya menjadi melimpah meskipun terjadi perubahan lingkungan.

Untuk nilai kelimpahan terendah secara berturut-turut berada pada kelas Cyanophyceae spesies Anabaena sp. diikuti kelas Bacillariophyceae spesies Pinnularia sp., Fragilaria sp., untuk kelas Chlorophyceae dengan spesies Coelastrum sp., Gonatozygon sp., Elakatothrix sp., Oocystis sp. dan Chaetophora sp. dengan rata-rata nilai kelimpahan sebesar $3 \mathrm{Ind} / \mathrm{L}$, karena hanya dapat dijumpai pada salah satu Stasiun pengamatan saja (Gambar 3). Hal ini dikarenakan dinamika kelimpahan fitoplankton dipengaruhi oleh faktor ketersediaan unsur hara (nutrien) serta kemampuan fitopankton untuk memanfaatkannya (Muharram, 2006), karena setiap spesies fitoplankton menunjukkan persyaratan yang berbeda terhadap nutrien (Sanders, dkk., 1987 dalam Abida, 2010).

Kelimpahan fitoplankton pada muara Sungai Hitam disajikan dengan nilai kelimpahan antar stasiun penelitian yang dapat dilihat pada Gambar 4.

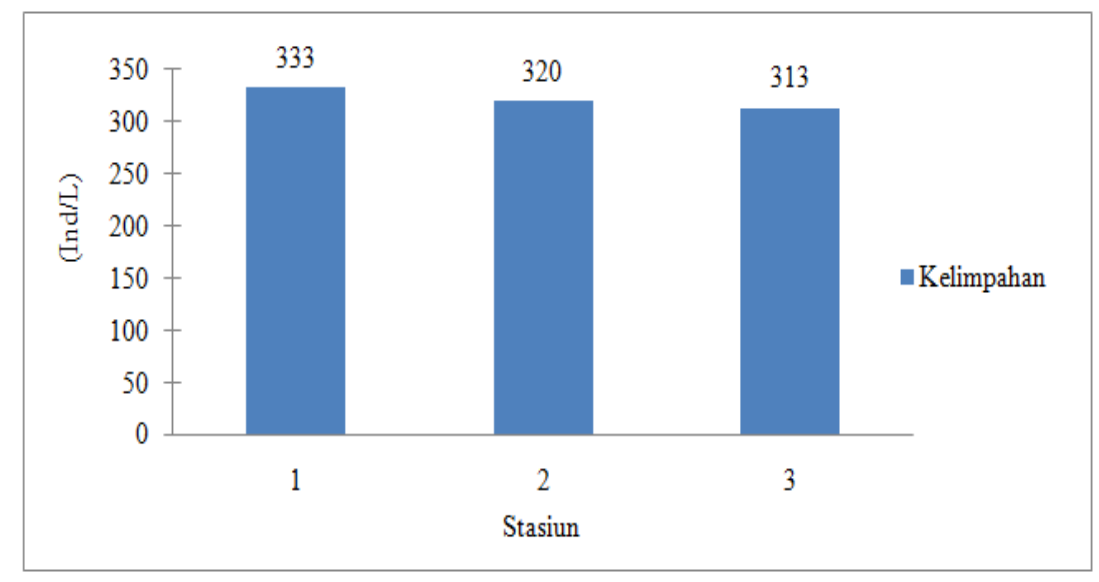

Gambar 4. Kelimpahan Fitoplankton Antar Stasiun Penelitian

Kelimpahan fitoplankton pada muara Sungai Hitam mengalami penurunan dari Stasiun 1 hingga Stasiun 3. Menurut pendapat Abida (2010) perbedaan nilai kelimpahan fitoplankton bisa disebabkan oleh keberadaan cahaya dalam kolom perairan, ketersediaan nutrien dan laju grazing oleh organisme lain. Berdasarkan hasil yang didapati nilai kelimpahan fitoplankton pada Stasiun 1 sebesar 333 Ind/L merupakan nilai kelimpahan tertinggi, hal ini diduga karena pengaruh dari kandungan nutrien yang tinggi dibandingkan dengan Stasiun pengamatan lainnya (Tabel 3). Senada dengan pendapat Sachlan (1982) dalam Rudiyanti (2016) kelimpahan fitoplankton yang tinggi sangat terpengaruh pada ketersediaan nutrien/unsur hara pada perairan yang juga tinggi. 
Kelimpahan fitoplankton terendah didapati pada Stasiun 3 yaitu sebesar $313 \mathrm{lnd} / \mathrm{L}$, hal ini diduga karena pengaruh dari kondisi perairan seperti aliran air akibat dari terjadinnya pertemuan arus datang dari laut akibat pecah gelombang laut dan arus keluar dari mulut muara. Kondisi ini mengakibatkan kondisi aliran air yang terlihat secara visual mengarah menjauhi lokasi Stasiun pengamatan, sehingga memberikan pengaruh terhadap perpindahan fitoplankton yang mengakibatkan nilai kelimpahan pada Stasiun 3 menurun dan dengan nilai kelimpahan terendah pada lokasi penelitian. Hal ini diperkuat oleh pendapatSuin (2002) dalam Suryanti (2016) penyebaran plankton, baik fitoplakton maupun zooplankton ditentukan oleh aliran air. Sehingga mempengaruhi komposisi dan kelimpahan plankton (Suryanti, 2016).

\section{Saprobik Indeks}

Nilai indeks saprobitas dapat dijadikan parameter penilaian tingkat pencemaran perairan yang ditinjau berdasarkan organisme penyusunnya seperti komposisi fitoplankton pada perairan muara Sungai Hitam yang tersaji pada tabel1.

Tabel 1. Saprobitas Perairan

\begin{tabular}{lll}
\hline Filum & Jumlah Spesies & Nilai Saprobitas \\
\hline Cyanophyta & 3 & \\
Dinophyta & 1 & 1.09 \\
Chlorophyta & 10 & (Kelompok $\beta$ - \\
Chrysophyta & 8 & Meso/Oligo saprobik)
\end{tabular}

Sumber: Data Primer (2017)

Berdasarkan hasil analisis data diindikasikan bahwa perairan muara Sungai Hitam termasuk dalam tingkat saprobitas $\beta$-Meso/Oligo saprobik, dimana hubungan antar bahan pencemar dengan nilai indeks saprobitas (SI) yang didapat memberikan gambaran bahwa perairan muara Sungai Hitam tergolong dalam kategori pencemaran bahan organik dan anorganik ringan (Suwondo, dkk., 2004). Pecemaran bahan organik erat kaitannya dengan kandungan nitrat dan fosfat (Rikardo, 2016), hal ini dikarenakan nitrat dan fosfat adalah nutrien yang diperlukan fitoplankton untuk tumbuh dan berkembang biak (Asih, 2014).

Walaupun tergolong dalam tingkat saprobitas perairan $\beta$ Meso/Oligo saprobik yang diindikasikan telah terjadi pencemaran bahan organik ringan (Tabel 1), namun kondisi perairan pada muara Sungai Hitam masih tergolong baik. Kondisi ini dilihat berdasarkan kandungan nitrat terukur sebesar $0,029 \mathrm{mg} / \mathrm{L}$ dan fosfat sebesar $0,042 \mathrm{mg} / \mathrm{L}$ berada dibawah konsentrasi kandungan bahan organik yang menyebabkan 46 


\begin{tabular}{lllllll}
9 & $\begin{array}{l}\text { Nitrit } \\
(\mathrm{mg} / \mathrm{L})\end{array}$ & 0.016 & 0.011 & 0.014 & 0.014 & - \\
10 & $\begin{array}{l}\mathrm{BOD} \\
(\mathrm{mg} / \mathrm{L})\end{array}$ & 3.1 & 1.3 & 2.1 & 2.2 & $20 \mathrm{mg} / \mathrm{L}^{\mathrm{e}}$ \\
11 & $\mathrm{DO}(\mathrm{mg} / \mathrm{L})$ & 6.7 & 6.9 & 6.7 & 6.8 & $>5 \mathrm{mg} / \mathrm{L}^{\mathrm{e}}$ \\
12 & $\mathrm{pH}$ & 6.1 & 6.4 & 7.1 & 6.5 & $6.5-8.0^{f}$ \\
\hline
\end{tabular}

Sumber: Data Primer (2017)

Keterangan:

a. Reynold (1990) dalam Hardiyanto (2012)

b. Milero dan Sohn (1992) dalam Yati (2015)

c. Mackentum (1969) dalam Yuliana (2012)

d. Kennish (1990) dalam Sudarsono (2012)

e. KepMen LH No.51 (2004)

f. Comel (1995) dalam Rudiyanti (2016)

Rata-rata kisaran parameter fisika yang terukur seperti suhu, kecepatan arus dan parameter kimia seperti salinitas, derajat keasaman $(\mathrm{pH})$, DO dan BOD berada dalam kondisi yang baik atau masih dapat menunjang kehidupan fitoplankton. Sedangkan untuk parameter kimia seperti konsentrasi kandungan nitrat, nitrit dan fosfat yang terukur pada lokasi penelitian (Tabel 2) diduga merupakan faktor pembatas yang memberikan pengaruh terhadap perkembangan atau pertumbuhan fitoplankton. Hal ini dikarenakan menurut Mackentum (1969) dalam Yuliana (2012) bahwa kandungan kadar fosfat dibawah 0,09 mg/L dapat menjadi faktor pembatas bagi pertumbuhan fitoplankton. Ditambahkan pendapat lainnya yang dikemukakan oleh Kennish (1990) dalam Sudarsono (2012) bahwa kandungan nitrat apabila kurang dari 0,44 mg/L turut menjadi faktor pembatas bagi pertumbuhan fitoplankton.

Maka berdasarkan atas berbagai pendapat diatas semakin memperkuat asumsi bahwa kandungan unsur hara pada lokasi penelitian yang terukur (Tabel 2), merupakan salah satu faktor yang mempengaruhi pertumbuhan fitoplankton pada lokasi penelitian yang tercermin dengan nilai kelimpahan yang rendah. Diperkuat oleh pendapat Sachlan (1982) dalam Rudiyanti (2016) bahwa kelimpahan fitoplankton dipengaruhi oleh keteresediaan unsur hara pada suatu perairan.

Untuk kecerahan perairan pada lokasi penelitian rata-rata sebesar 34,6 cmdengan nilai kecerahan (\%)rata-rata sebesar 78,4\% dalam kondisi kedalaman perairan rata-rata sebesar $46,5 \mathrm{~cm}$ (Tabel 2) yang diduga memberikan pengaruh terhadap perkembangan kehidupan fitoplankton. Kondisi ini terlihat dari nilai kelimpahan fitoplankton yang tergolong rendah pada lokasi penelitian yaitu hanya sebesar 322 Ind/L. Hal ini dikarenakan menurut Nybakken (1988) dalam Anwar (2015) bahwa kelimpahan fitoplankton dipengaruhi oleh intensitas cahaya, karena intensitas cahaya 48 
yang terlalu tinggi atau kuat akan mengakibatkan fitoplankton yang tidak tahan akan mati (Nybakken, 1988 dalam Anwar, 2015).

\section{KESIMPULAN}

Berdasarkan hasil penelitian pada muara Sungai Hitam, Kabupaten Bengkulu Tengah, Provinsi Bengkulu ditemukan 4 kelas fitoplankton dengan 22 spesies yaitu dengan komposisi spesies terbanyak terjadi pada kelompok fitoplankton kelas Chlorophyceaedan yang terendah terjadi pada kelas Dinophyceae. Kelimpahan fitoplankton tertinggi didapati pada Stsiun 1 dengan nilai kelimpahan $333 \mathrm{Ind} / \mathrm{L}$ dan kelimpahan terendah terdapat pada Stasiun 3 dengan nilai kelimpahan fitoplakton 313 Ind/L. Rata-rata kelimpahan fitoplankton pada Muara Sungai Hitam didapati sebanyak 322 Ind/Lyang mencerminkan perairan dengan kesuburan rendah. Perairan muara Sungai Hitam tergolong dalam tingkat saprobitas perairan $\beta$-Meso/Oligo saprobik dengan kategori tingkat pencemaran bahan organik ringan.

\section{DAFTAR PUSTAKA}

Abida, W. I. 2010. Struktur Komunitas Dan Kelimpahan Fitoplankton Di Perairan Muara Sungai Porong Sidoarjo. Kelautan 3 (1).

Ali, A. Soemarno. Purnomo, M. 2013. Kajian Kualitas Air Dan Status Mutu Air Sungai Metro Kecamatan Sukun Kota Malang. Bumi Lestari 13 (2) : 265-274.

Anwar, A. 2015.Studi Kelimpahan Dan Sebaran Phytoplankton Secara Vertikal Di Pesisir Perairan Kuricaddi. Balik Diwa 6 (2).

Asih, P. 2014. Produktivitas Primer Fitoplankton Di Perairan Desa Malang Rapat Kabupaten Bintan. Skripsi. Program Studi Ilmu Kelautan. FIKP. Universitas Maritim Raja Ali Haji, Kepulauan Riau.

Hendrajat, A. E., Pantjara, B. 2016. Kajian Kelimpahan, Indeks Biologi, Dan Produktivitas Primer Plankton Di Perairan Muara Sungai Takkalasi Kabupaten Barru. Prosiding Forum Inovasi Teknologi Akuakultur, 2016.

Hardiyanto, R., Suherman, H., Pratama, R.I. 2012. Kajian Produktivitas Primer Fitoplankton Di Waduk Saguling, Desa Bongas Dalam Kaitannya Dengan Kegiatan Perikanan. Perikanan Dan Kelautan 3 (4) : 51-59.

Keputusan Menteri Lingkungan Hidup Nomor 51. 2004. Tentang Baku Mutu Air Laut Untuk Biota Hidup. 
Mizuno, T. 1979. Ilustrations of The Freshwater Plankton of Japan. Hoikusha Publishing Co., LTD. 17, I-Chome, Uemachi, Higashi-ku, Osaka, 540 Japan.

Muharram, N. 2006.Struktur Komunitas Perifiton Dan Fitoplakton Di Bagian Hulu Sungai Ciliwung Jawa Barat. Skripsi. Departemen Manajemen Sumberdaya Perairan. Fakultas Perikanan dan IImu Kelautan.Institut Pertanian Bogor.

Rikardo, I. 2016. Keragaman Fitoplankton Sebagai Indikator Kualitas Perairan Muara Sungai Jang Kota Tanjungpinang.Skripsi. Program Studi Manajemen Sumberdaya Perairan. FKIP. Universitas Maritim Raja Ali Haji, Kepulauan Riau.

Rudiyanti, S. 2016. Pengaruh Unsur Hara Terhadap Kelimpahan Fitoplankton Sebagai Bioindikator Pencemaran Di Sungai Gambir Tembalang Kota Semarang. Diponegoro Journal Of Maquares 5 (1) : 32-37.

Sudarsono.2012. Struktur Komunitas Fitoplankton Di Perairan Kelurahan Sei Jang, Kecamatan Bukit Bastari Kota Tanjungpinang. Skripsi. Program Studi Manajemen Sumberdaya Perairan. FKIP. Universitas Maritim Raja Ali Haji, Kepulauan Riau.

Sunarto, 2008.Karakteristik Biologi Dan Peranan Plankton Bagi Ekosistem Laut.Fakultas Pertanian dan IImu Kelautan, Universitas Padjadjaran.

Suryanti, E. 2016. Keragaman Fitoplankton Sebagai Indikator Kualitas Perairan Kampung Gisi Kecamatan Teluk Bintan Kabupaten Bintan. Skripsi. Jurusan Manajemen Sumberdaya Perairan. FIKP. Universitas Maritim Raja Ali Haji, Kepulauan Riau.

Suwondo, Elya F., Dessy dan Mahmud, A. 2004. Kualitas Biologi Perairan Sungai Senapelan, Sago Dan Sail Di Kota Pekanbaru Berdasarkan Bioindikator Plankton Dan Bentos. Biogenesis 1 (1) : 15-20.

Wulandari, D. Y. 2015. Struktur Komunitas Fitoplankton Dan Tingkat Kesuburan Perairan Pesisir Tanggerang. Tesis. Fakultas Pascasarjana Institut Pertanian Bogor, Bogor.

Yamaji, I. 1979. Ilustrations of The Marine Plankton of Japan. Hoikusha Publishing Co., LTD. 17, I-Chome, Uemachi, Higashi-ku, Osaka, 540 Japan.

Yati, N. 2015. Analisis Kelimpahan Fitoplankton Di Perairan Pantai Kahyapu Pulau Enggano Kabupaten Bengkulu Utara Provinsi Bengkulu. Skripsi. Program Studi IImu Kelautan. Fakultas Pertanian. Universitas Bengkulu, Bengkulu. 
Yuliana.2012. Implikasi Perubahan Ketersediaan Nutrien Terhadap Perkembangan Pesat (Blooming) Fitoplankton Di Perairan Teluk Jakarta. Disertasi. Fakultas Pascasarjana Institut Pertanian Bogor, Bogor.

Zahidin, M. 2008. Kajian Kualitas Air Di Muara Sungai Pekalongan Ditinjau Dari Indeks Keanekaragaman Makrobenthos Dan Indeks Saprobitas Plankton. Tesis. Program Studi Magister Manajemen Sumberdaya Pantai. Universitas Diponegoro, Semarang. 